\title{
Current iodine nutrition status and progress toward elimination of iodine deficiency disorders in Jazan, Saudi Arabia
}

Rashad Mohammed Ali Alsanosy ${ }^{1,2}$, Abdelrahim Mutwakel Gaffar ${ }^{1,3 *}$, Husam Eldin Elsawi Khalafalla1, Mohamed Salih Mahfouz ${ }^{1}$, Abdel Naser Shaaban Zaid ${ }^{4}$ and Ibrahim Ahmed Bani ${ }^{1}$

\begin{abstract}
Background: The term iodine deficiency disorders (IDD) refers to all the effects of iodine deficiency on growth and development in human and animal populations that can be prevented by correction of the iodine deficiency. The objective of this paper was to determine the iodine nutrition status among schoolchildren in the Jazan Region of the Kingdom of Saudi Arabia (KSA), by measuring urinary iodine concentrations and by clinical assessments of goiter rate.

Methods: A school-based cross-sectional survey was conducted in the Jazan region of southwestern KSA from May to November 2010. A total of 311 children, aged 6-13 years, drawn from 12 schools, were selected by a three-stage cluster random sampling method. Data on sociodemographic characteristics were collected using a structured questionnaire. Urine samples were collected and physical examinations were conducted to determine the presence or absence of goiter. Data were analyzed using SPSS version 17.0. Chi square and independent $t$-tests were used for proportions and mean comparisons between groups.

Results: Out of 360 selected children, 311 were examined. There were 131 males (42\%) and 180 females (58\%). The median urinary iodine concentration (UIC) of the study group was $421 \mu \mathrm{g} / \mathrm{L}$. The study population proportion with UIC > $300 \mu \mathrm{g} / \mathrm{L}$ was $74 \%$ with a higher proportion among males and urban populations. The proportion of children with UIC of $100-300 \mu \mathrm{g} / \mathrm{L}$ was only $21 \%$ and was significantly higher among females compared with males ( $p<$ 0.001). Only about $3 \%$ of the children had a median UIC less than $50 \mu \mathrm{g} / \mathrm{L}$. The prevalence of total goiter rate (TGR) among the sample of schoolchildren in Jazan was $11 \%$, with significant variations between rural and urban populations and by gender.

Conclusions: The present study demonstrates a remarkable achievement in Universal Salt lodization (USI) and IDD elimination goals in the Jazan area. However, UIC levels reflect excessive iodine intake and may put the population at risk of adverse health consequences like iodine-induced hyperthyroidism and autoimmune thyroid diseases.
\end{abstract}

Keywords: Iodine nutrition, Saudi Arabia, Jazan, USI

\footnotetext{
* Correspondence: mutwakel73@gmail.com

${ }^{1}$ Family and Community Medicine Department, Faculty of Medicine, Jazan

University, PO Box 2531, 45142 Jazan, Saudi Arabia

${ }^{3}$ Member of the International Council for Control of lodine Deficiency

Disorders (ICCIDD), Ottawa, ON, Canada

Full list of author information is available at the end of the article
} 


\section{Background}

The term iodine deficiency disorders (IDD) refers to all the effects of iodine deficiency on growth and development in human and animal populations that can be prevented by correction of the iodine deficiency [1]. IDD in the most severe form includes cretinism, stillbirth and miscarriage, and increased infant mortality [1]. In developing countries about 38 million newborns every year remain unprotected from the lifelong consequences of brain damage associated with IDD [2]. A recent study estimated that 266 million school-age children and two billion of the general population worldwide have insufficient iodine intake [3].

In the Middle East and North Africa region the situation of IDD control varies considerably between countries. Only the Islamic Republic of Iran and Tunisia have achieved IDD control goals [4]. Iraq, Afghanistan and Pakistan were classified as suffering from severe IDD while Morocco, Sudan and the Kingdom of Saudi Arabia (KSA) were considered as suffering from moderate IDD problems $[4,5]$.

Universal Salt Iodization (USI) is a strategy to ensure sufficient intake of iodine by all individuals was recommended by the WHO and UNICEF Joint Committee on Health Policy in 1994 [6]. Some experts believe that universal salt iodization may be the most successful public health effort of the past two decades [2] and a remarkably cost-effective public health goal [7].

UNICEF estimates that less than $20 \%$ of households in the developing world were using iodized salt in the early 1990 s, and by 2000, the average had jumped to some $70 \%$. By 2006, around 120 countries were implementing salt iodization programs [2]. In 2007, worldwide 12 countries have optimal iodine status and iodine intake is more than adequate, or even excessive, in 34 countries [3], an increase from 27 in 2003 [8]. In the Middle East and North Africa region, 64\% of households consume adequately iodized salt with wide variation between countries [5].

The targets for sustainable IDD elimination include process and impact indicators. The process indicators are; (1) $100 \%$ of all salt produced and imported is iodized; (2) 95\% of all iodized salt imported and produced is adequately iodized; (3) $90 \%$ of households are using adequately iodized salt; and (4) 100\% of all districts have reached the goal of USI, i.e. > 90\% of households are using adequately iodized salt. The impact indicators are: (1) population median urinary iodine concentration (UIC) is $100-300 \mu \mathrm{g} / \mathrm{L}$; (2) proportion of samples with UIC levels below $100 \mu \mathrm{g} / \mathrm{L}$ is $<50 \%$; and (3) proportion of samples with UIC levels below $50 \mu \mathrm{g} / \mathrm{L}$ [6].

In the KSA a national cross-sectional epidemiological survey for studying iodine status was conducted among
Saudi schoolchildren aged 8-10 years in 1997 [9]. The median national UIC was $180 \mu \mathrm{g} / \mathrm{L}$ and the total goiter rate (TGR) ranged from $8 \%$ to $30 \%$. Nationally the proportion of the population with UIC less than 100 was $23 \%$. The southern province of Jazan had the lowest median UIC $(110 \mu \mathrm{g} / \mathrm{L})$ and the highest percentage $(45 \%)$ of subjects with a UIC $<100 \mu \mathrm{g} / \mathrm{L}$ [9]. The IDD control program using the USI strategy started in 1997, and the Saudi Standards, Metrology and Quality Organization (SASO) recommend that iodine content of salt must be 70-100 ppm in all food salt [10]. Since the national survey in 1997, no follow up survey or monitoring system has taken place [4] to assess the iodine nutrition status in the population neither nationally or in the Jazan region.

The objective of this paper is to determine the iodine nutrition status among schoolchildren in the Jazan Region of the KSA, by measuring the UIC and by clinical assessment of the goiter rate.

\section{Methods \\ Setting}

This was a cross-sectional, observational study conducted in the Jazan region during the period from May to November 2010. The Jazan region is one of the 13 regions of the KSA, located on the tropical Red Sea coast in the southwestern KSA. Jazan covers an area of $11,671 \mathrm{~km}^{2}$, including some 5,000 villages and towns. Adjacent to the region are 100 islands, including the largest island of Farasan. The Jazan region runs along the Red Sea coast for almost $300 \mathrm{~km}$ and is a highly relatively populated region with a total population of 1.5 million.

\section{Sampling method}

A three-stage cluster random sampling procedure was adopted to select target children from 12 schools representing different governorates of the Jazan region. The 12 schools were randomly selected from the list of schools of the target age group in the region and then one class was randomly selected in each of the selected schools. Proportionate to Population Size (PPS) sampling technique was used to determine the required number of children from classes as recommended by the WHO for iodine nutrition surveys. We aimed to obtain a sample of 300 children for this study [6].

\section{Data collection tools and techniques}

Data regarding participants' sociodemographic characteristics were collected from the children using a structured questionnaire. A casual urine sample of $\sim 10 \mathrm{~mL}$ also was collected in a plain tube from each child participating in the survey and stored in a refrigerator $\left(4^{\circ} \mathrm{C}\right)$. An aliquot of urine (5-6 mL) was transferred to a tube with a tight cap and was shipped to the International 
Council for the Control of Iodine Deficiency Disorders (ICCIDD) iodine reference laboratory in the $\mathrm{Nu}$ tritional Intervention Research Unit (NIRU) of the Medical Research Council (MRC), Cape Town, South Africa, for determination of iodine concentrations. Another aliquot of urine $(5-6 \mathrm{~mL})$ was kept as a reference material at the Jazan University Medical Research Centre.

Urine samples were analyzed using a modified microplate method based on manual digestion with ammonium persulfate followed by the colorimetric determination of the Sandel-Kolthoff reaction by using 96-multiwell plates and an absorbance microplate reader at $405 \mathrm{~nm}$. The absolute iodine value is expressed in $\mu \mathrm{g} / \mathrm{L}[6,11]$.

\section{Quality control}

Internal quality control (QC) samples were prepared by collecting random urine samples over a 24-hour period, which were either diluted with deionized water or spiked with a known potassium iodate solution to obtain samples at low, median and high iodine concentrations. These QC samples are normally used to determine the inter- and intra-assay precision of the method. During the analysis of study samples the analytical intra-assay precision of the method was determined by calculating the coefficient of variation (\% CV) of four analyses of six urine pools ranging from 49.6 to $239.8 \mu \mathrm{g} / \mathrm{L}$. Inter-assay precision was established by assaying three urine pools (low, medium and high) in 8 to 12 microplate runs. The intra-assay CVs were 5.0\%, 2.2\%, $0.5 \%, 1.4 \%, 0.6 \%$ and $6.6 \%$ at $49.6,100.0,120.7,129.2,175.2$ and $239.8 \mu \mathrm{g} / \mathrm{L}$ iodine, respectively. The inter-assay $\mathrm{CVs}$ were $7.8 \%$, $4.8 \%$ and $7.1 \%$ at $47.9,124.6$ and $230.4 \mu \mathrm{g} / \mathrm{L}$ iodine, respectively.

\section{Clinical assessment}

Neck examination for goiter was done by trained medical doctors for all children. The ICCIDD uses a simplified goiter classification: grade 0 , no palpable or visible goiter; grade 1, palpable but not visible when neck is in normal position; and grade 2, palpable and visible when the neck is in normal position [6].

\section{Statistical analysis}

Results are presented as means \pm standard deviation (SD), medians and frequencies as well as percentages. Comparisons between two means were conducted using Student's $t$-test for continuous variables. The chi-square test was used to compare some selected categorical variables. Before the $t$-test was used, normality assumptions were assessed using the Kolmogorov-Smirnov test and homogeneity of variances were tested using the Levene's test. All statistical analyses were performed using
SPSS, version 17 (SPSS Inc., Chicago, IL, USA). P-value less than 0.05 was considered statistically significant.

\section{Ethical considerations}

Ethical approval was obtained from the Research Ethics Committee in the Medical Research Center-Jazan University, and the study was approved by the regional education authorities. Written informed consent was obtained from the parents of participating children.

\section{Results}

Out of 360 selected children 311 were examined and provided salt and urine samples (response rate $=86 \%$ ). The mean age of the children was 10 years (SD 1.6), and ranged between 6 to 13 years. There were 131 males (42.1\%) and 180 females (57.9\%). Rural dwellers formed the biggest proportion of children (72.2\%); the urban population constituted $(24.8 \%)$ of the children.

Table 1 presents the number of participants, median, mean and SD of UIC and percentage of participants with UIC > $300 \mu \mathrm{g} / \mathrm{L}$. The median UIC was $517 \mu \mathrm{g} / \mathrm{L}$ and was significantly higher among male participants $(P$-value $<0.001)$. However, no significant difference $(P=0.230)$ was observed between the mean UIC for rural and urban children. The proportion of the population with UIC > $300 \mu \mathrm{g} / \mathrm{L}$ was $74 \%$ with a higher proportion among males and urban populations.

Table 2 shows the UIC $(\mu \mathrm{g} / \mathrm{L})$ of school children according to residence and gender in the Jazan region. The proportion of the population with UIC $100-300 \mu \mathrm{g} / \mathrm{L}$ was only $21 \%$ and was significantly higher among females than males $(P<0.001)$. Only $3 \%$ of the population had a UIC less than $50 \mu \mathrm{g} / \mathrm{L}$. The proportion of the population with a UIC more than $200 \mu \mathrm{g} / \mathrm{L}$ was $87 \%$.

Table 3 shows the distribution of schoolchildren according to goiter prevalence. The prevalence of TGR among schoolchildren in Jazan was $11 \%$ with significant variations between rural and urban populations and gender. The TGR was higher among rural than urban

Table 1 The sample size, median, and mean (SD) urinary iodine concentration (UIC) and percentage of subjects with urinary iodine concentration $>300 \mu \mathrm{g} / \mathrm{L}$

\begin{tabular}{|c|c|c|c|c|c|}
\hline \multirow[t]{2}{*}{ Item } & \multicolumn{3}{|c|}{ Urinary iodine concentration $(\mu \mathrm{g} / \mathrm{L})$} & \multirow{2}{*}{\multicolumn{2}{|c|}{$\begin{array}{c}\% \text { with iodine } \\
\text { concentration } \\
>300 \mu \mathrm{g} / \mathrm{L}\end{array}$}} \\
\hline & $\mathbf{N}$ & Median & Mean (SD) & & \\
\hline \multicolumn{6}{|l|}{ Gender } \\
\hline Male & 131 & 484 & $516 \pm 213 \quad P<0.001$ & 88 & $P<0.001$ \\
\hline Female & 180 & 369 & $399 \pm 245$ & 64 & \\
\hline \multicolumn{6}{|l|}{ Residency } \\
\hline Rural & 234 & 415 & $440 \pm 230 \quad P=0.230$ & 71 & $P<0.05$ \\
\hline Urban & 77 & 436 & $475 \pm 200$ & 83 & \\
\hline Total & 311 & 420 & $449 \pm 239$ & 74 & \\
\hline
\end{tabular}


Table 2 Urinary iodine concentration ( $\mu \mathrm{g} / \mathrm{L}$ ), according to residence and gender in Jazan

\begin{tabular}{|c|c|c|c|c|c|}
\hline \multirow{3}{*}{$\begin{array}{l}\text { UIC } \\
\text { range }\end{array}$} & \multicolumn{2}{|c|}{ Residence no. (\%) } & \multicolumn{2}{|c|}{ Gender no. (\%) } & \multirow[t]{3}{*}{ Total } \\
\hline & Rural & Urban & Male & Female & \\
\hline & $n=234$ & $n=77$ & $n=131$ & $n=180$ & \\
\hline $0-49$ & $8(3.4)$ & - & - & $8(4.4)$ & $8(2.6)$ \\
\hline $50-99$ & $7(3.0)$ & - & $1(0.8)$ & $6(3.3)$ & $7(2.3)$ \\
\hline $100-199$ & $22(9.4)$ & $3(3.9)$ & $5(3.8)$ & $20(11.1)$ & $25(8.0)$ \\
\hline $200-299$ & $30(12.8)$ & $10(13.0)$ & $10(7.6)$ & $30(16.7)$ & $40(12.9)$ \\
\hline$\geq 300$ & $167(71.4)$ & $64(83.1)$ & $115(87.8)$ & $116(64.4)$ & $231(74.3)$ \\
\hline$P$-value & \multicolumn{2}{|c|}{0.085} & \multicolumn{2}{|c|}{$<0.001$} & \\
\hline
\end{tabular}

population $(P=0.004)$ and higher in female than male participants $(P=0.012)$.

\section{Discussion}

The three most important indicators used in IDD surveillance, as well as in initial problem assessment, are goiter prevalence, urinary iodine excretion in a population, and thyroid function tests [6]. The WHO advises researchers to combine at least two indicators, one morphological and one laboratory test. A 1997 survey found that $23 \%$ of the national population and $45 \%$ of the Jazan region population had UIC below $100 \mu \mathrm{g} / \mathrm{L}$, although their median urinary iodine concentration was within the normal range. Additionally, goiter prevalence ranged from $25 \%$ to $30 \%$ in costal and mountain areas in the southern region. The authors recommend that the country needs to implement an IDD control program [9]. In this study the researchers used both urinary iodine excretion and goiter prevalence to assess the iodine nutrition status.

\section{Urinary iodine}

In our study the median UIC among the studied population in the Jazan area was $421 \mu \mathrm{g} / \mathrm{L}$ compared with $110 \mu \mathrm{g} / \mathrm{L}$ in the 1997 survey in Jazan, and $180 \mu \mathrm{g} / \mathrm{L}$ at the national level [9]. This median UIC reflects excessive iodine intake in the population based on WHO cut-off points [6]. The median UIC is significantly higher among male participants $(484 \mu \mathrm{g} / \mathrm{L})$ than female participants $(369 \mu \mathrm{g} / \mathrm{L})(P$-value $<0.001)$. The median UIC in Jazan,

Table 3 Distribution of schoolchildren according to goiter prevalence

\begin{tabular}{|c|c|c|c|c|c|}
\hline \multirow{2}{*}{$\begin{array}{l}\text { Goiter } \\
\text { rate }\end{array}$} & \multicolumn{2}{|c|}{ Residence no. (\%) } & \multicolumn{2}{|c|}{ Gender no. (\%) } & \multirow[t]{2}{*}{ Total } \\
\hline & Rural & Urban & Male & Female & \\
\hline Grade 0 & $202(86.3)$ & $73(100)$ & $121(95.3)$ & $145(85.6)$ & $275(89.6)$ \\
\hline Grade 1 & $18(7.7)$ & - & $5(3.9)$ & $13(7.2)$ & $10(5.9)$ \\
\hline Grade 2 & $14(6.0)$ & - & $1(0.8)$ & $13(7.2)$ & $14(4.6)$ \\
\hline Total & $234(100)$ & $73(100)$ & $127(100)$ & $180(100)$ & $307(100)$ \\
\hline$P$-value & \multicolumn{2}{|c|}{0.004} & \multicolumn{2}{|c|}{0.012} & \\
\hline
\end{tabular}

KSA, is the highest in the Gulf and Arab region and similar to that reported in Ecuador $(420 \mu \mathrm{g} / \mathrm{L})$, Uganda $(464 \mu \mathrm{g} / \mathrm{L})$ and the Democratic Republic of the Congo $(495 \mu \mathrm{g} / \mathrm{L})$ [5].

Based on the UIC cut-off points recommended by the WHO regarding iodine nutrition status, only $8 \%$ of the population has adequate iodine intake (UIC 100$199 \mu \mathrm{g} / \mathrm{L}$ ), 13\% above requirements (UIC 200-299 $\mu \mathrm{g} / \mathrm{L}$ ), and $74 \%$ with excessive iodine intake [6]. Only $5 \%$ of children have UIC less than $100 \mu \mathrm{g} / \mathrm{L}$ compared with $45 \%$ in 1997 [9].

The population of Jazan was subjected to excessive iodine intake with a risk of adverse health consequences like iodine-induced hyperthyroidism and autoimmune thyroid diseases [6,12-14]. A similar phenomenon was observed in 34 countries after the implementation of USI, which emphasized the importance of establishing and strengthening the monitoring system to guide USI to provide optimal iodine nutrition and protect against excessive intake [6,15].

\section{Goiter rate}

Goiter prevalence in the studied region ranged from $0 \%$ in urban areas to $14 \%$ in rural areas. The prevalence of goiter was significantly higher $(P$-value $=0.012)$ among female participants (14\%) than male participants (11\%). Al-Nuaim et al. in 1997 reported a goiter prevalence rate of $4 \%$ in Gizan or Jazan and 22\% in the Aseer area [9]. Similar prevalence in the Aseer region (24\%) was reported by Abu-Eshy et al. in 2001 [16]. Goiter prevalence in Jazan is much less than what is reported by many countries in the Eastern Mediterranean region. In Yemen the TGR was $16.8 \%$ [5,17]. In the Gulf region the TGR in 2010 was $40.4 \%$ in the United Arab Emirates, $10 \%$ in Oman and $1.7 \%$ in Bahrain [5]. On the other hand in other Arab countries the TGR is 65\% in Algeria, $36.3 \%$ in Tunisia, 33.5\% in Jordan, 30.9\% in Mauritania, $25.7 \%$ in Lebanon, and $21.4 \%$ in Egypt [5]. In Iran, the TGR was reduced from $68.0 \%$ in 1989 to only $5.7 \%$ in 2007 through implementation of a comprehensive IDD control program [18].

The salt iodization standard in the KSA as issued by SASO recommends that the amount of iodine to be between $70-100 \mathrm{ppm}$ in the form of potassium iodate. This recommendation is the highest in the Gulf region [10] and higher than that recommended by the WHO which is 15-40 ppm [6]. Since the start of the salt iodization program in 1997, now more than $99 \%$ of the study population in Jazan uses iodized salt. Three hundred and eleven random salt samples were tested to determine the iodine content; $44.1 \%$ had iodine concentrations higher than $40 \mathrm{ppm}$.

$\mathrm{Al}$-Attas quantified the iodine content of foods in the KSA and concluded that food consumed by Saudis 
appears to have an adequate iodine concentration [19]. The high level of UIC may be explained, in light of the previous study finding by Al-Attas, by the high level of iodine concentrations in salt, increased consumption of dairy products, and ready-prepared salty meals that may have substantially changed the amount of salt and iodine consumed by the school population.

There is a need to reconsider the level of salt iodization in the KSA following the latest WHO recommendation in light of local dietary patterns. It will be important to provide optimal iodine nutrition and to protect the population from the adverse health consequences of excessive iodine intake.

\section{Conclusion}

The present study demonstrates a remarkable progress in achieving USI and IDD elimination goals in the Jazan area of the KSA. However, the UIC reflects excessive iodine intake and may put the population at risk of adverse health consequences like iodine-induced hyperthyroidism and autoimmune thyroid diseases. The levels of iodine in the salt were substantially higher than the WHO recommendation and revision of salt specifications is highly recommended. Establishing surveillance and monitoring systems will protect the population and help in guiding the implementation of USI in the country.

\section{Study limitations}

Logistical issues of the study including send samples to South Africa for analysis. For this reason the sample size is small to detect the differences between clusters, although it is quite reasonable for the study. Now that the capacity of the Medical Research Center is developed, further studies could be done and samples analysis will be conducted locally. The schools in the country do not provide meals for their students. Also, no school nutrition program is implemented in the country and the food industry is required to use iodized salt for all processed food. Thus, the results reflect the iodine nutrition in the community.

\section{Competing interest}

The authors have no conflicts of interest to declare.

\section{Authors' contribution}

RMA, HEE, ASZ and IAB prepared the project proposal; RMA, AMG and MSM designed this research paper; MSM and AMG performed data analysis; AMG and RMA wrote the manuscript. HEE, IAB, and ASZ provided significant input on the manuscript. All authors read and approved the final manuscript.

\section{Sources of funding}

This work was funded by the Medical Research Center, Jazan University, KSA, under grant project No. 1000.

\section{Acknowledgements}

We would like to thank Prof. David Haxton (ICCIDD Executive Director), Dr Izzeldin Alsharief (ICCIDD, Gulf Regional Coordinator), and Prof. Pieter Jooste (Nutritional Intervention Research Unit of the Medical Research
Council, Cape Town, South Africa) for their collaboration in the analysis of the urine samples. We appreciate the efforts of the Education Directorate of the Jazan Region, administrative staff, teachers and school health professionals for coordination of data collection.

\section{Author details}

${ }^{1}$ Family and Community Medicine Department, Faculty of Medicine, Jazan University, PO Box 2531, 45142 Jazan, Saudi Arabia. ${ }^{2}$ Medical Research Centre, Jazan University, Jazan, Saudi Arabia. ${ }^{3}$ Member of the International Council for Control of lodine Deficiency Disorders (ICCIDD), Ottawa, ON, Canada. ${ }^{4}$ Surgery Department, Faculty of Medicine, Jazan University, Jazan, Saudi Arabia

Received: 11 March 2012 Accepted: 13 November 2012

Published: 20 November 2012

\section{References}

1. Zimmermann MB: lodine deficiency. Endocr Rev 2009, 30(4):376-408.

2. UNICEF: Sustainable Elimination of lodine Deficiency, Progress since the 1990 World Summit for Children. New York: UNICEF; 2008:1-29.

3. de Benoist B, McLean E, Andersson M, Rogers L: Iodine deficiency in 2007: global progress since 2003. Food Nutr Bull 2008, 29(3):195-202.

4. Azizi F, Mehran L: Experiences in the prevention, control and elimination of iodine deficiency disorders: a regional perspective. East Mediterr Health J 2004, 10(6):761-770.

5. Global Scorecard: Network for Sustainable Elimination of Iodine Deficiency. New York: UNICEF; 2010.

6. WHO, UNICEF, ICCIDD: Assessment of iodine deficiency disorders and monitoring their elimination: a guide for programme managers. Geneva: World Health Organization; 2007.

7. Mannar MGV: lodized Salt for the Elimination of lodine Deficiency Disorders. In New Delhi: Manzar Khan. Edited by Hetzel BS. New Delhi: Oxford University Press; 2004

8. Andersson M, Takkouche B, Egli I, Allen HE, de Benoist B: Current global iodine status and progress over the last decade towards the elimination of iodine deficiency. Bull World Health Organ 2005, 83(7):518-525.

9. Al-Nuaim AR, Al-Mazrou Y, Kame M, Al-Attas O, Al-Daghari N, Sulimani R: lodine deficiency in Saudi Arabia. Ann Saudi Med 1997, 17(3):293-297.

10. Food Grade Salt: GSO 1843/2007. 2007:1-15.

11. Sullivan KM, May S, Maberly G: Urinary lodine Assessment: A Manual on Survey Methods. Atlanta GA: Program Against MicronutrientMalnutrition (PAMM), Department of International Health, Rollins School of Public Health at Emory University; 2000.

12. Alsayed A, Gad AM, Abdel-Baset H, Abdel-Fattah A, Ahmed A, Azab A: Excess Urinary lodine Is Associated With Autoimmune Subclinical Hypothyroidism among Egyptian Women. Endocr J 2008, 55(3):601-605.

13. Mooij P, de Wit HJ, Drexhage HA: A high iodine intake in Wistar rats results in the development of a thyroid-associated ectopic thymic tissue and is accompanied by a low thyroid autoimmune reactivity. Immunology 1994, 81(2):309-316.

14. Zhao J, Wang P, Shang L, Sullivan KM, van der Haar F, Maberly G: Endemic goiter associated with high iodine intake. Am J Public Health 2000, 90(10):1633-1635.

15. Zimmermann MB, Aeberli I, Torresani T, Bürgi H: Increasing the iodine concentration in the Swiss iodized salt program markedly improved iodine status in pregnant women and children: a 5-y prospective national study. Am J Clin Nutr 2005, 82(2):388-392.

16. Abu-Eshy S, Abolfotouh M, Al-Naggar Y: Endemic goitre in schoolchildren in high and low altitude areas of Asir region, Saudi Arabia. Saudi Med J 2001, 22(2):146-149.

17. Zein A, Al-Haithamy S, Obadi Q, Noureddin S: The epidemiology of iodine deficiency disorders (IDD) in Yemen. Public Health Nutr 2000, 3(2):245-252.

18. Delshad H, Mehran L, Azizi F: Appropriate lodine Nutrition in Iran: 20 Years of Success. Acta Med Iran 2010, 48(6):361-366.

19. Al-Attas O, Sulimani R: lodine concentrations in Saudi staple foods. Saudi Med J 1993, 14(4):322-324.

doi:10.1186/1471-2458-12-1006

Cite this article as: Alsanosy et al:: Current iodine nutrition status and progress toward elimination of iodine deficiency disorders in Jazan, Saudi Arabia. BMC Public Health 2012 12:1006. 